\title{
Pengembangan Sistem Informasi Pencatatan Riwayat Dan Notifikasi Penjadwalan Donor Darah Berbasis Website Menggunakan Framework Codeigniter
}

\author{
Development of History Recording and Notification Information \\ System Website Based Blood Donor Scheduling Using Codeigniter \\ Framework \\ Rosalina Yani Widiastuti, Endang Setyawati, \& Angela Marici Uba Langobelen \\ 1) Sekolah Tinggi Ilmu Komputer (STIKOM) Yos Sudarso, Indonesia \\ *Coresponding Email: angelamarici010@gmail.coom
}

\begin{abstract}
Abstrak
Palang Merah Indonesia merupakan sebuah organisasi perhimpunan nasional di Indonesia yang bergerak dalam bidang sosial kemanusiaan. Salah satu kegiatan utama PMI adalah donor darah. Saat ini dalam menangani kebutuhan donor darah, UDD PMI Kabupaten Banyumas memiliki sistem yang membantu dalam proses donor yaitu SIMDONAR. SIMDONAR ini merupakan sistem informasi dari IT pusat yang diberikan kepada UDD PMI Kabupaten Banyumas dalam pengoperasian donor darah, namun dalam beberapa aspek donor darah seperti pencatatan riwayat donor dan notifikasi penjadwalan donor kepada pendonor masih belum ada sehingga belum dapat berjalan dengan efisien. Pendataan dalam sistem pencatatan riwayat donor darah masih belum dapat tercatat dengan baik sehingga menyebabkan pendonor juga tidak dapat mengetahui riwayat donor yang terakhir, kapan dan sudah berapa kali pendonor tersebut telah mendonor, juga belum adanya notifikasi penjadwalan donor darah bagi pendonor, hal ini membuat informasi yang tersampaikan ke pendonor tidak lengkap sehingga pendonor bingung dalam mengambil tindakan kapan harus mendonor lagi. Oleh sebab itu, untuk mendukung kelancaran pada sistem donor darah perlu dibangun kembali sistem informasi yang sesuai dan dapat memberikan solusi bagi proses pencatatan riwayat donor darah pada UDD PMI Kabupaten Banyumas. Tujuan dari sistem ini adalah dapat meningkatkan proses pencatatan dan notifikasi penjadwalan donor darah sehingga dapat memberikan informasi yang akurat dan efisien. Manfaat dari sistem ini adalah Membantu memberikan informasi terkait catatan riwayat donor bagi UDD PMI Kabupaten Banyumas agar dapat mengetahui catatan riwayat donor dari para pendonor, juga membantu pendonor untuk mengetahui riwayat donor atau sudah berapa kali pendonor tersebut melakukan donor darah, dan sebagai salah satu media untuk memperkenalkan kampus Stikom Yos Sudarso kepada masyarakat umum. Dalam kasus ini metode pengembangan sistem menggunakan metode prototype model. Berdasarkan hasil uji manfaat menunjukan nilai rata-rata dari nilai Eficiency adalah $98,33 \%$, nilai Usability $94,33 \%$, nilai Correctness $95,56 \%$, nilai Integrity $96,67 \%$, dan nilai Testability $96,67 \%$. dari hasil uji manfaat tersebut dapat disimpulkan bahwa pengembangan sistem ini dapat diterapkan dan digunakan untuk mempermudah poses pencatatan riwayat donor darah dan notifikasi penjadwalan donor darah di UDD PMI Kabupaten Banyumas. Kata Kunci : Sistem Informasi; Website; prototype model, PMI; Donor Darah.
\end{abstract}

\begin{abstract}
The Indonesian Red Cross is a national association organization in Indonesia that is engaged in the social and humanitarian field. One of PMI's main activities is blood donation. Currently, in handling the need for blood donors, UDD PMI Banyumas Regency has a system that helps in the donor process, namely SIMDONAR. SIMDONAR is an information system from the central IT provided to UDD PMI Banyumas Regency in the operation of blood donors, but in some aspects of blood donation, such as donor recording and notification of donor scheduling to donors, there is still no available so that it can run efficiently. Data collection in the blood donor history recording system still cannot be recorded properly, causing donors to also not be able to know the history of the last donor, when and how many times the donor has donated, there is also no notification of blood donor scheduling for donors, this makes the information conveyed to donors is incomplete so that donors are confused in taking action when to donate again. Therefore, to support the smooth running of the blood donor system, it is necessary to rebuild an appropriate information system that can provide a solution for the process of recording blood donation history at UDD PMI Banyumas Regency. The purpose of this system is to provide accurate and efficient information related to blood donation history records, and scheduling notifications to officers and donors. The benefit of this system is that it helps provide information related to donor history records for UDD PMI Banyumas Regency so that they can find out donor history records from donors, also helps donors to find out donor history or how many times the donor has donated blood. In this case, the system development method uses the prototype model method. Based on the results of the benefit test, the average value of the Efficiency value is $98.33 \%$, the Usability value is $94.33 \%$, the Correctness value is $95.56 \%$, the Integrity value is $96.67 \%$, and the Testability value is $96.67 \%$. From the results of the benefit test, it can be concluded that the development of this system can be applied and used to facilitate the process of recording blood donor history and notification of blood donor scheduling at UDD PMI Banyumas Regency.

Keywords: Information System; Website; prototype model; PMI, Blood Donation.
\end{abstract}

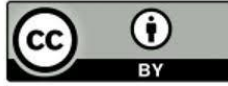




\section{PENDAHULUAN}

Sistem Informasi terus berkembang semakin canggih dari masa ke masa dan pemanfaatannya sebagai salah satu alat bantu dalam bidang kehidupan sudah sangat luas. Dengan semakin pesatnya peran serta teknologi informasi dalam segala aspek kehidupan, sekarang ini mendorong berbagai bidang kehidupan seperti bidang pendidikan, bidang kesehatan, bidang sosial masyarakat, dan beberapa bidang lainnya untuk dapat mensiasati strategi sistem informasi yang tepat agar tercapainya maksud dan tujuan yang diharapkan. Keakuratan, ketepatan dan kecepatan menjadi faktor penting dalam pengolahan data, maka dari itu dibutuhkan suatu sistem informasi yang terintegrasi dalam hal menyajikan, dan mengumpulkan data-data dengan lebih akurat.

Pada Palang Merah Indonesia terutama pada bagian unit donor darah, yang bergerak dalam bidang pencarian, pendataan sangat membutuhkan sistem administrasi yang baik agar dalam menjalankan kegiatannya dengan lebih efisien. Salah satu pemanfaatan teknologi komputer dalam kehidupan sosial masyarakat adalah kegiatan donor darah. Donor darah adalah aktivitas rutin yang diadakan oleh unit donor darah pusat maupun daerah yang berada di bawah naungan Palang Merah Indonesia (PMI).

Pada tatanan instansi UDD PMI Kabupaten Banyumas terutama pada bagian unit donor darah yang bergerak dalam pendataan itu membutuhkan sistem administrasi riwayat yang baik agar dalam proses pencatatan atau penggunaan pengolahan data dapat berjalan secara efisien. Palang Merah Indonesia (PMI) berdiri pada tahun 1945, tepatnya ditanggal 17 september. Palang Merah Indonesia (PMI) merupakan sebuah organisasi perhimpunan nasional di Indonesia yang bergerak dalam bidang sosial kemanusiaan. Salah satu kegiatan utama PMI adalah donor darah. Saat ini dalam menangani kebutuhan donor darah, UDD PMI Kabupaten Banyumas memiliki sistem yang membantu dalam proses donor yaitu SIMDONAR. SIMDONAR ini merupakan sistem informasi dari IT pusat yang diberikan kepada UDD PMI Kabupaten Banyumas dalam pengoperasian donor darah, namun dalam beberapa aspek donor darah seperti pencatatan riwayat donor dan notifikasi penjadwalan donor kepada pendonor masih belum ada sehingga belum dapat berjalan dengan efisien. Pendataan dalam sistem pencatatan riwayat donor darah masih belum dapat tercatat dengan baik sehingga menyebabkan pendonor juga tidak dapat mengetahui riwayat donor yang terakhir, kapan dan sudah berapa kali pendonor tersebut telah mendonor, juga belum adanya notifikasi 
Vol 1, No. 1, Agustus 2018: 1 -10

penjadwalan donor darah bagi pendonor, hal ini membuat informasi yang tersampaikan ke pendonor tidak lengkap sehingga pendonor bingung dalam mengambil tindakan kapan harus mendonor lagi. Oleh sebab itu, untuk mendukung kelancaran pada sistem donor darah perlu dibangun kembali sistem informasi yang sesuai dan dapat memberikan solusi bagi proses pencatatan riwayat donor darah pada UDD PMI Kabupaten Banyumas.

Berdasarkan uraian permasalahan yang ada, sangat menarik untuk melakukan penelitian terhadap sistem donor darah, agar kegiatan donor darah dapat berjalan secara efisien, maka penulis akan membuat sebuah website dengan judul penelitian "Pengembangan Sistem Informasi Pencatatan Riwayat dan Notifikasi Penjadwalan Donor Darah Berbasis Website Menggunakan Framework Codeigniter (Studi Kasus: UDD PMI Kabupaten Banyumas).

\section{METODE PENELITIAN}

Prototyping yaitu teknik pengembangan yang digunakan untuk penggambaran sistem sehingga user dapat melihat gambaran dari sistem yang akan dikembangkan. Biasanya digunakan karena user tidak terlalu menguasai sistem (Mulyani S, 2017).

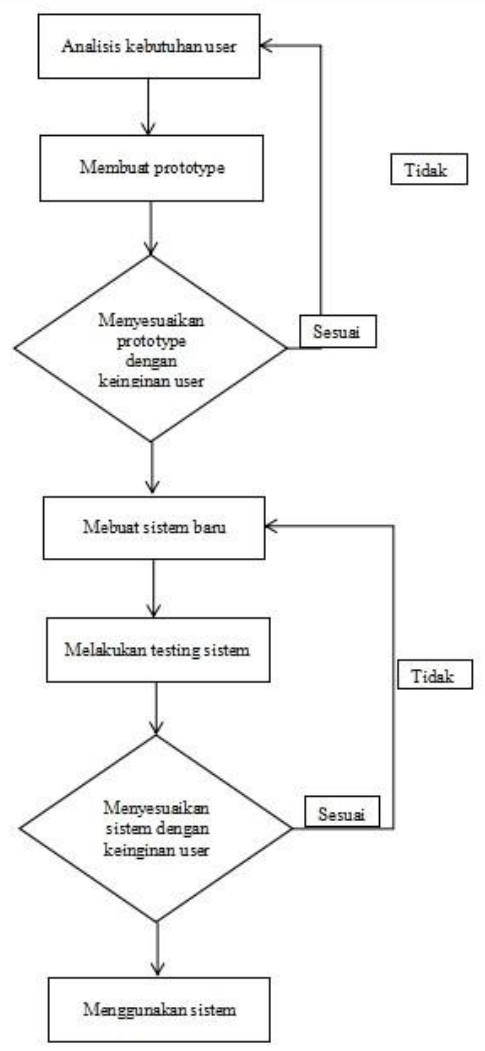


Rosalina Yani Widiastuti, Endang Setyawati, \& Angela Marici Uba Langobelen, Pengembangan Sistem

\section{Desain Sistem}

Gambar 1. Metode Prototype (Mulyani S 2017)

Pada tahap ini dibuat desain tampilan sistem dan use case diagram yang menjelaskan peran aktor dalam menggunakan sistem. Claas diagram menjelaskan pemetaan struktur sistem dengan model kelas-kelas, atribut, operasi, dan hubungan antara obyek. Activity diagram memiliki kegunaan untuk menjelaskan aluur dari penggunaan sistem
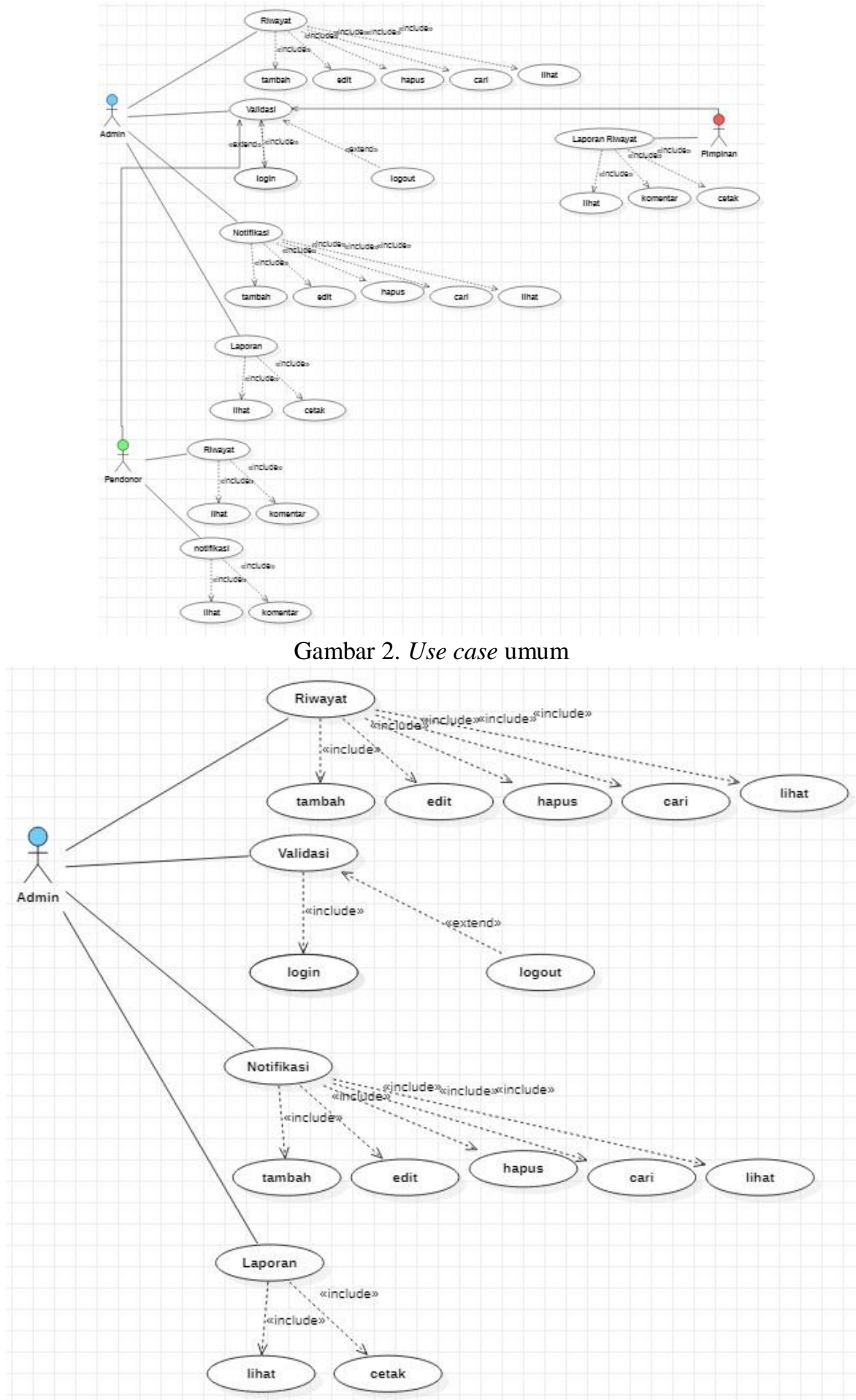

Gambar 3. Use Case Admin 
Vol 1, No. 1, Agustus 2018: 1 -10

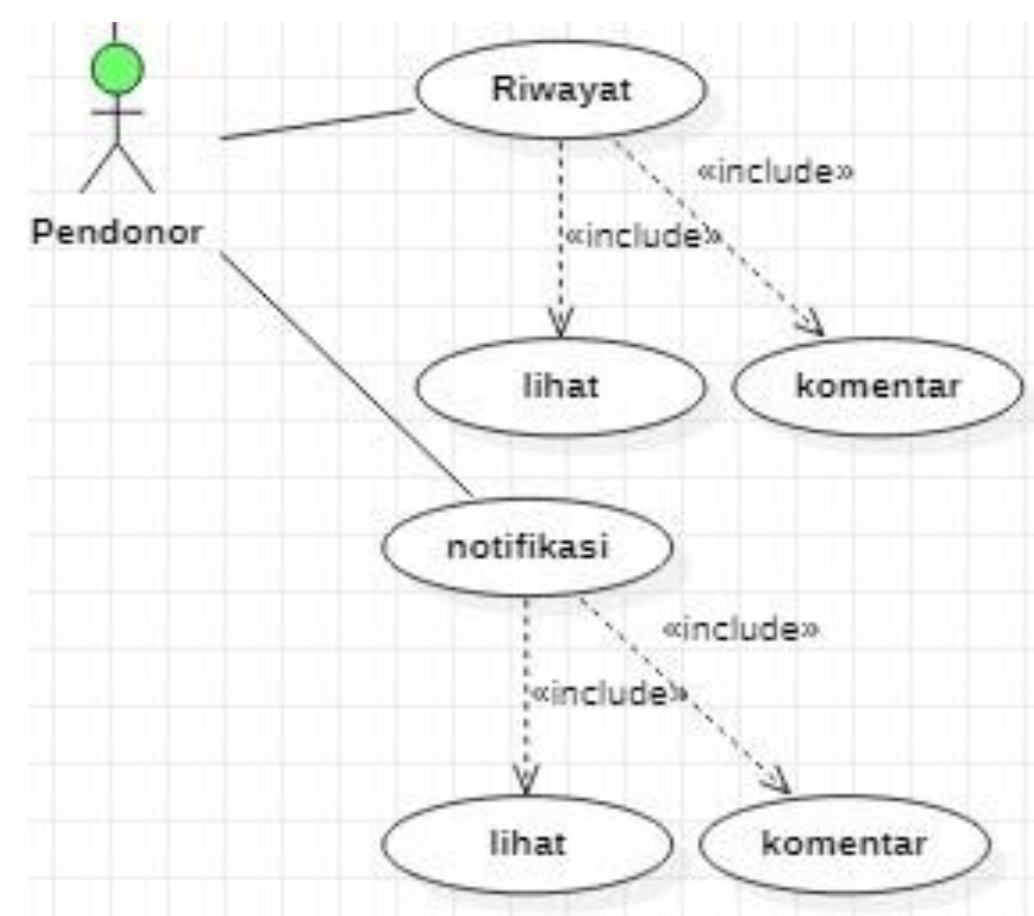

Gambar 4. Use Case Pendonor

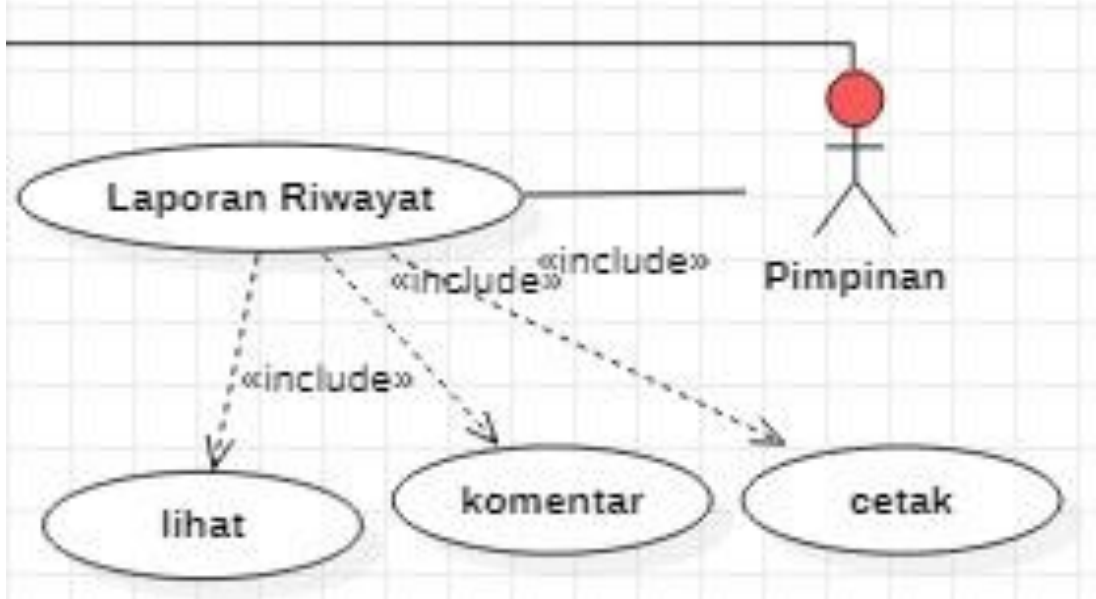

Gambar 5. Use Case Pimpinan 
Rosalina Yani Widiastuti, Endang Setyawati, \& Angela Marici Uba Langobelen, Pengembangan Sistem

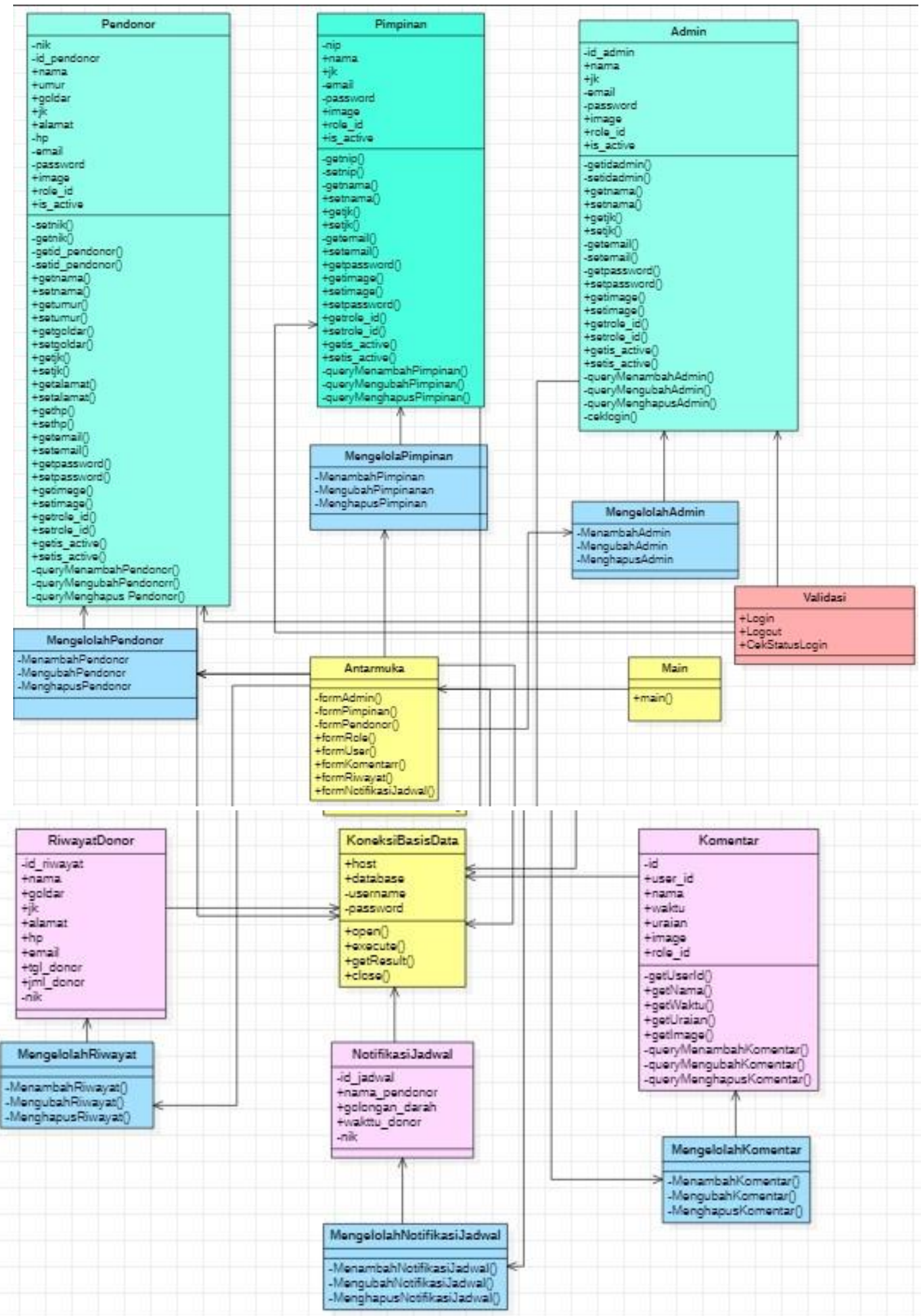

Gambar 5. Class Diagaram 
Vol 1, No. 1, Agustus 2018: 1 -10

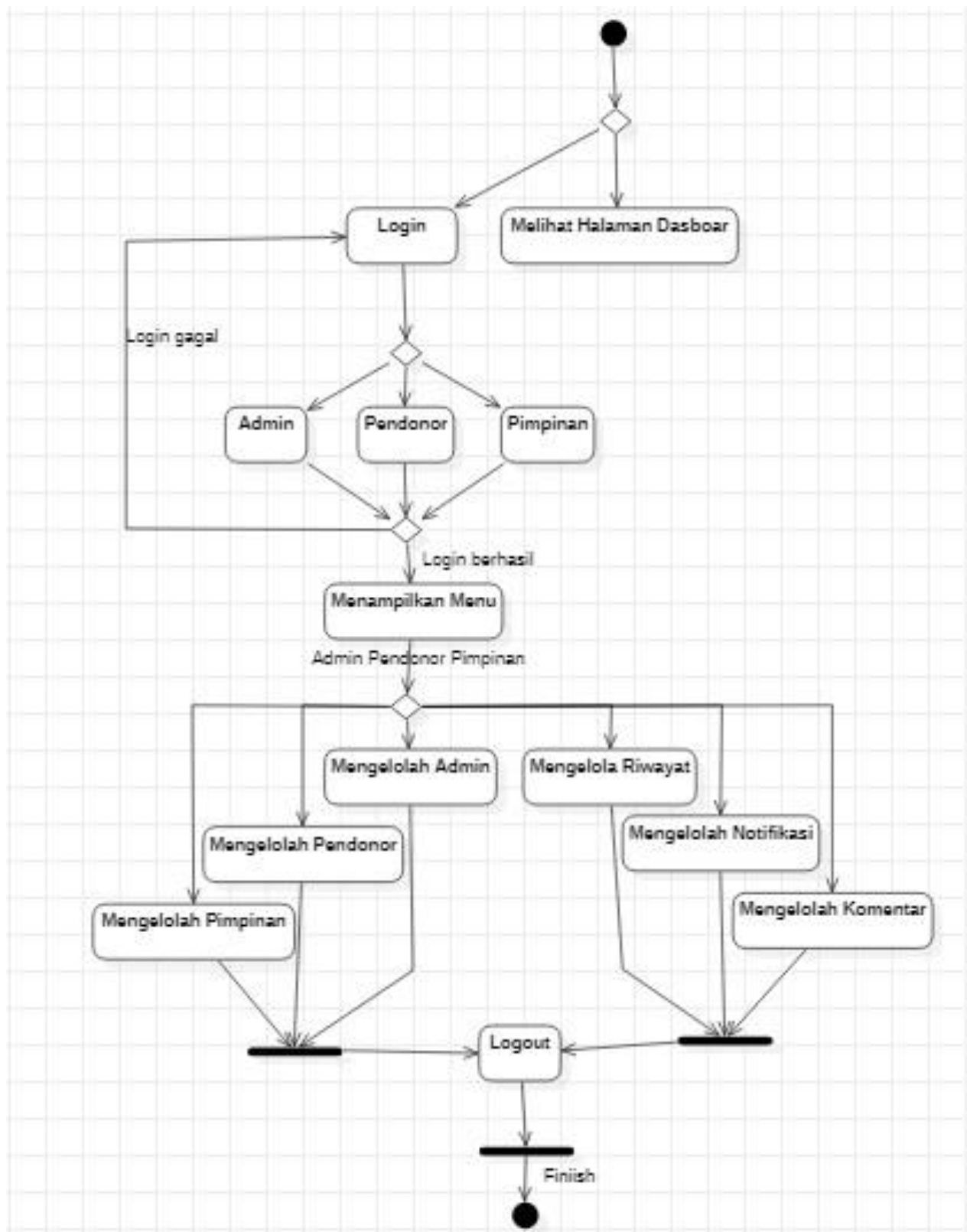

Gambar 6. Activity Diagram 
Rosalina Yani Widiastuti, Endang Setyawati, \& Angela Marici Uba Langobelen, Pengembangan Sistem

\section{HASIL DAN PEMBAHASAN}

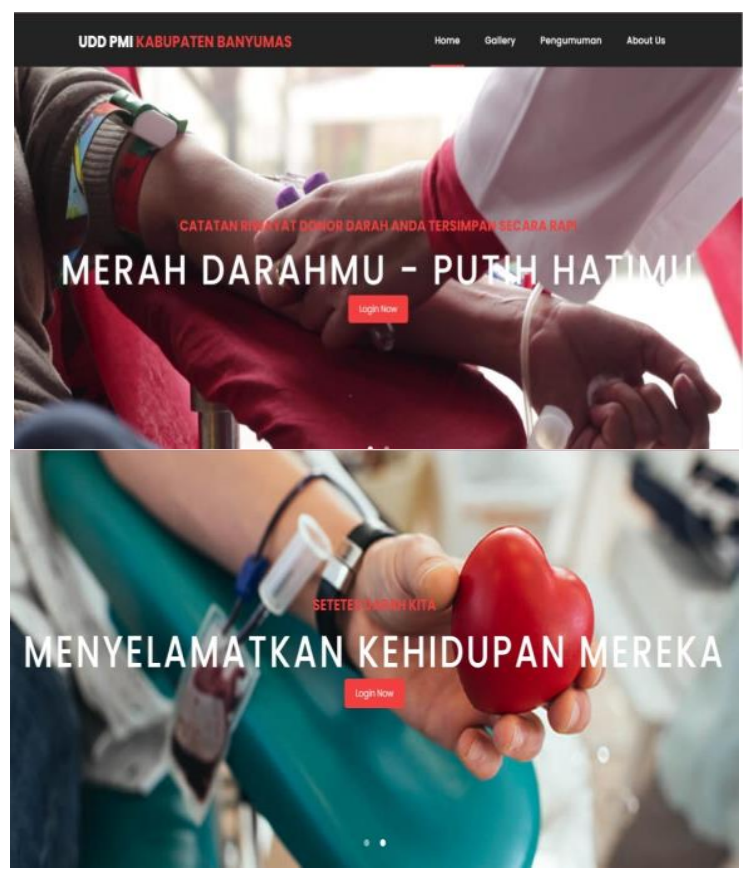

Gambar 6. Halaman Dashboard

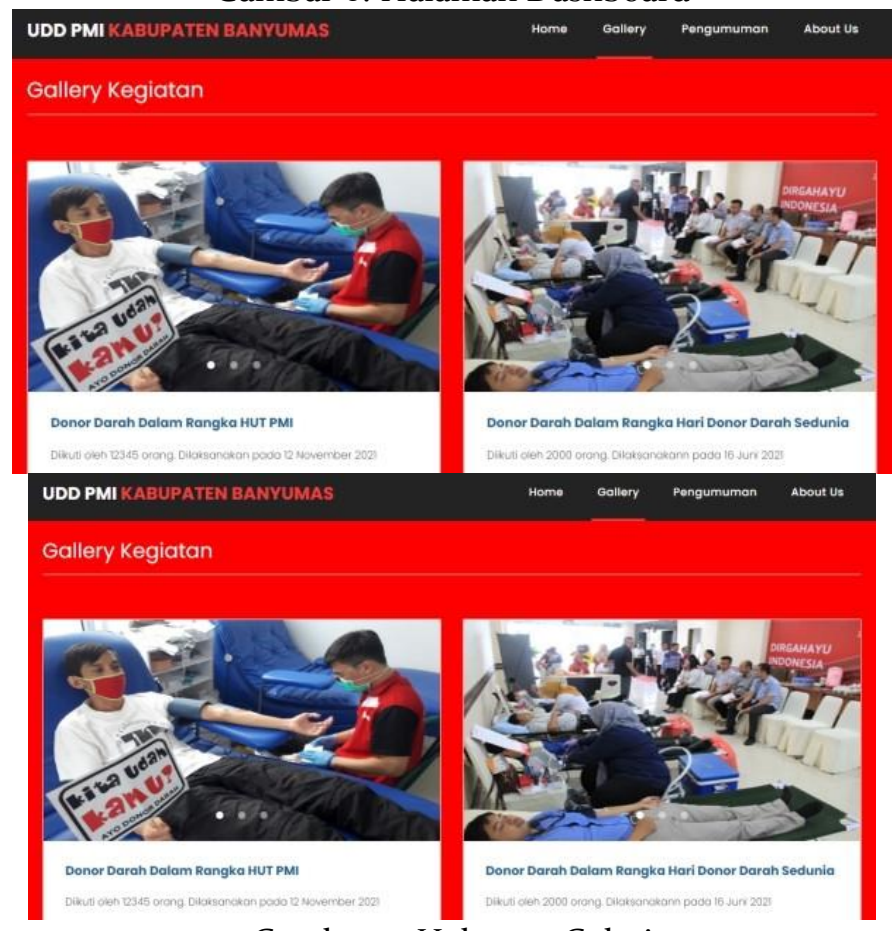

Gambar 7. Halaman Galeri 
Vol 1, No. 1, Agustus 2018: 1 -10

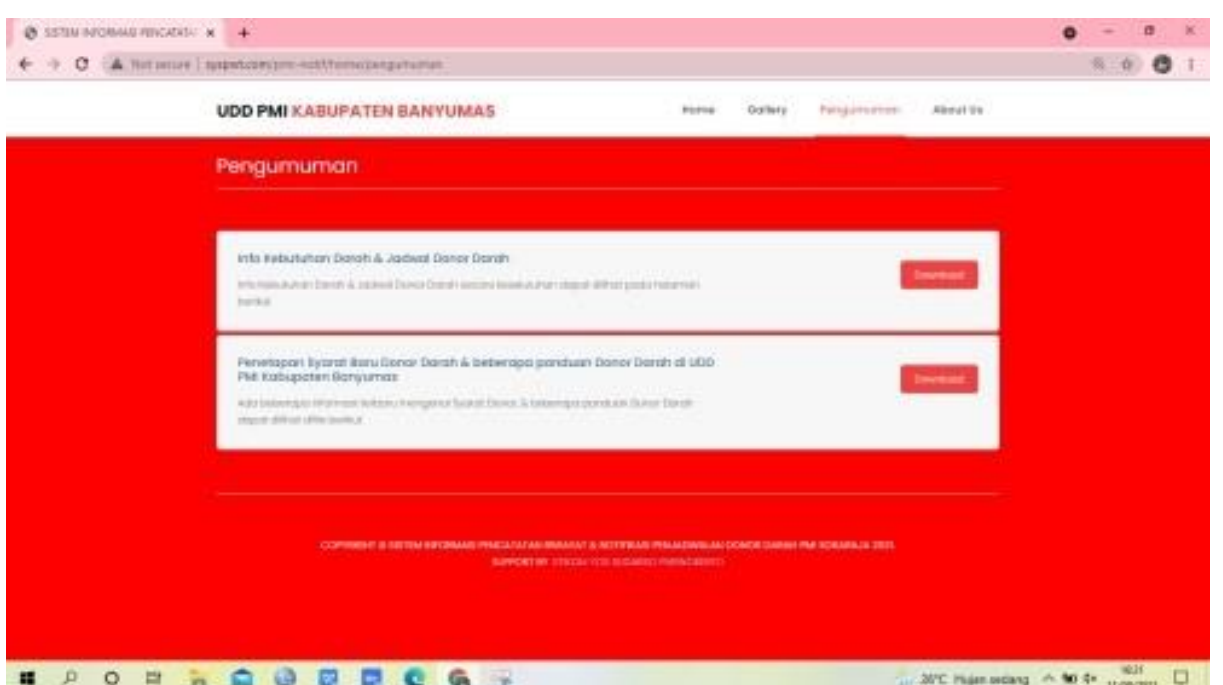

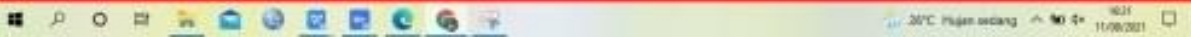

Gambar 9. Halaman Pengumuman

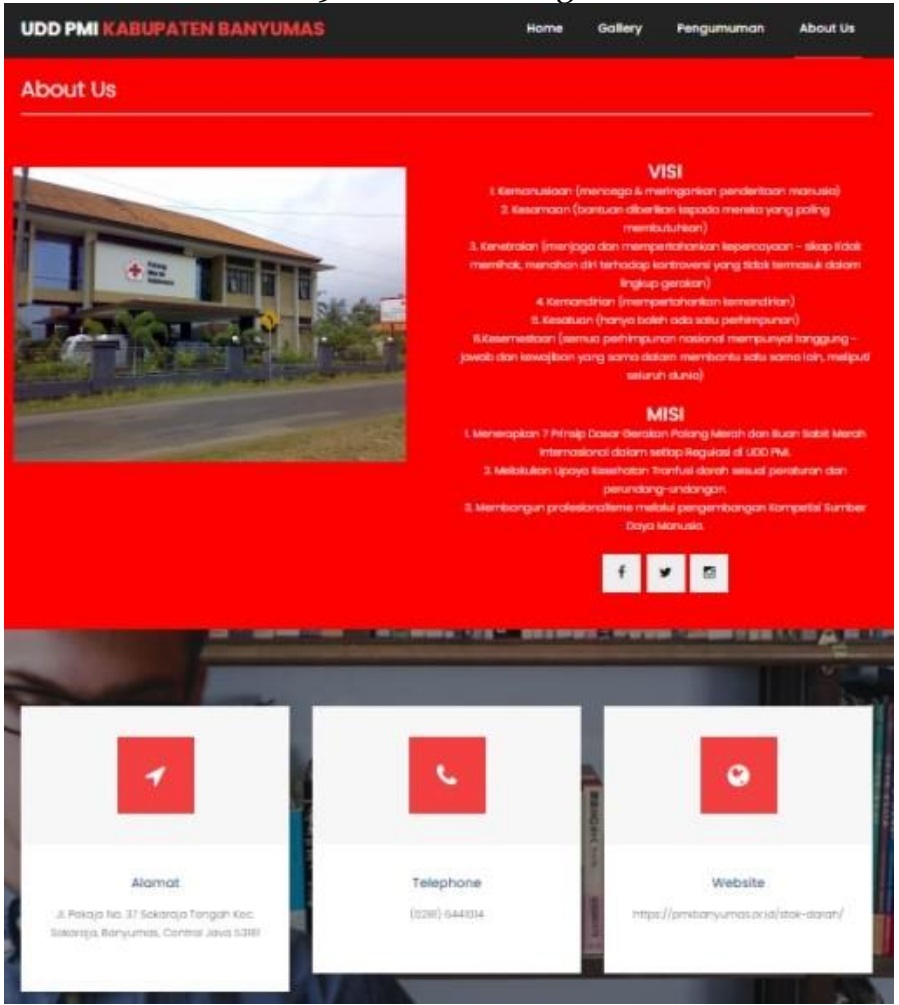

Gambar 10. Halaman About

\section{Pengujian Sistem}

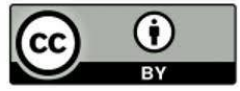

This work is licensed under a Creative Commons Attribution 4. 
Rosalina Yani Widiastuti, Endang Setyawati, \& Angela Marici Uba Langobelen, Pengembangan Sistem

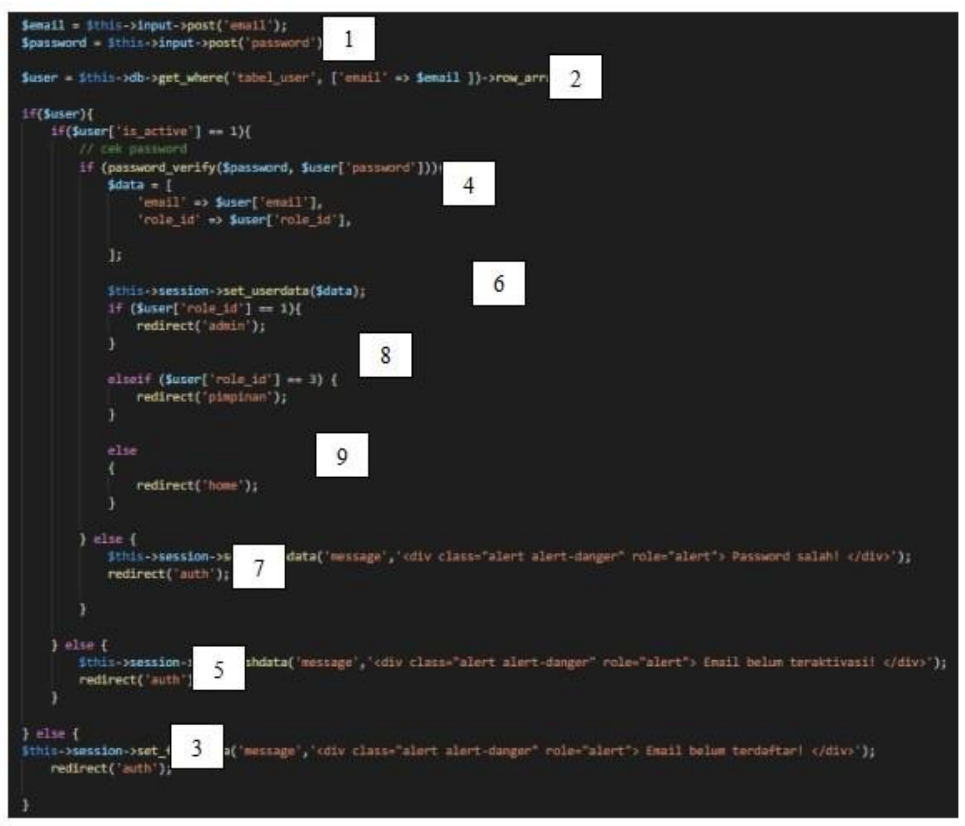

White Box testing Login

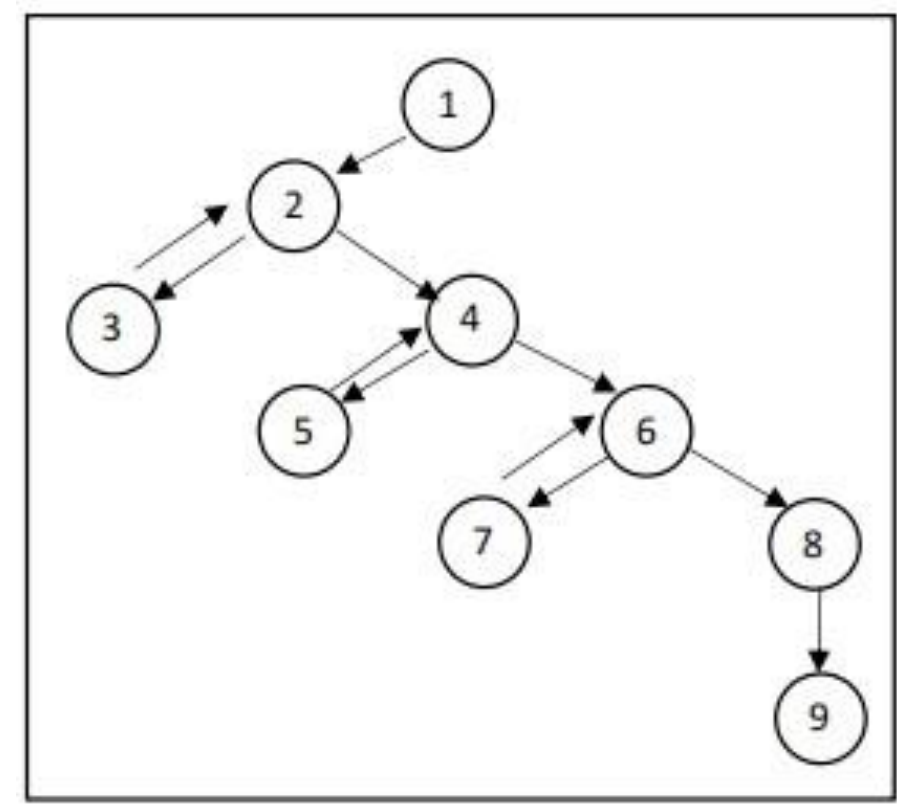

Gambar 67. Flowgraph Fungsi Login

Pada gambar flowgraph di atas dapat dihitung kompleksitas cyclomatic proses dengan menggunakan rumus:

$$
\mathrm{V}(\mathrm{G})=\mathrm{E}-\mathrm{N}+2
$$

$$
\begin{gathered}
\mathrm{V}(\mathrm{G}) \text { : cyclomatic complexity } \\
\mathrm{E} \text { : total jumlah edge } \\
\mathrm{N} \text { : total jumlah node }
\end{gathered}
$$

Dapat dihitung sebagai berikut:

$$
\mathrm{V}(\mathrm{G})=11-9+2
$$

\footnotetext{
色 $\mathrm{http://journal.mahesacenter.org/index.php/incoding}$ 
Vol 1, No. 1, Agustus 2018: 1 -10

$$
\mathrm{V}(\mathrm{G})=4
$$

Dari hasil perhitungan cyclomatic complexity di atas menunjukan jumlah pengujian yang harus dijalankan dengan path sebagai berikut: Path 1: 1-2-4-6-8-9

Path 2: 1-2-4-6-7-6-8-9

Path 3: 1-2-4-5-4-6-7-8-9

Path 4: 1-2-3-2-4-5-6-7-8-9

\begin{tabular}{|c|c|c|c|c|c|c|}
\hline Deskripsi & Test Case & Input & Output & $\begin{array}{l}\text { Kriteria } \\
\text { Evaluasi }\end{array}$ & $\begin{array}{c}\text { Output } \\
\text { yang benar }\end{array}$ & $\begin{array}{c}\text { Kesimp } \\
\text { ulan }\end{array}$ \\
\hline $\begin{array}{l}\text { Pengujian } \\
\text { Login }\end{array}$ & $\begin{array}{l}\text { Masulsan usemame } \\
\text { dan Password } \\
\text { Klik tombollogin } \\
\text { Tampil login berhasil }\end{array}$ & $\begin{array}{l}\text { Usemame } \\
\text { dan } \\
\text { Password }\end{array}$ & $\begin{array}{l}\text { Semua } \\
\text { berhasi } \\
1 \text { dan } \\
\text { tidak } \\
\text { error }\end{array}$ & $\begin{array}{l}\text { Tampilan } \\
\text { setelah klik: } \\
\text { login sesuai } \\
\text { prosecurur }\end{array}$ & $\begin{array}{c}\text { Sermua } \\
\text { sudah di } \\
\text { alkses dan } \\
\text { tidak ada } \\
\text { error }\end{array}$ & berhssil \\
\hline $\begin{array}{l}\text { Usemame } \\
\text { salah (tidalk } \\
\text { terdaftar) }\end{array}$ & $\begin{array}{l}\text {-Masulikn } \\
\text { Username yang salah } \\
\text { - Kliktombol login } \\
\text {-Tampilan peringatan } \\
\text { bahwa username } \\
\text { tidak terdaftar }\end{array}$ & $\begin{array}{l}\text { Username } \\
\text { dan } \\
\text { Passicard }\end{array}$ & $\begin{array}{c}\begin{array}{c}\text { Terdap } \\
\text { at }\end{array} \\
\text { peringa } \\
\text { tan } \\
\text { bahwa } \\
\text { uiserna } \\
\text { me } \\
\text { tidak } \\
\text { terdafta } \\
\text { I }\end{array}$ & $\begin{array}{l}\text { Peringatan } \\
\text { username } \\
\text { salah } \\
\text { (tidak } \\
\text { terdaftar) } \\
\text { sesuai } \\
\text { prosedur }\end{array}$ & $\begin{array}{l}\text { Terdapat } \\
\text { peringatan } \\
\text { bahwa } \\
\text { username } \\
\text { tidal } \\
\text { terdaftar }\end{array}$ & Berhasil \\
\hline $\begin{array}{c}\text { Password } \\
\text { salsh }\end{array}$ & $\begin{array}{c}\text {-Masulklan } \\
\text { Passirond yang salah } \\
\text { - Kliktombol login } \\
\text {-Tampilan peringatan } \\
\text { bahwa passirard } \\
\text { salah }\end{array}$ & $\begin{array}{l}\text { Csername } \\
\text { dan } \\
\text { Passrard }\end{array}$ & 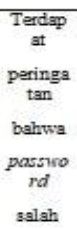 & $\begin{array}{l}\text { Peringatam } \\
\text { passiond } \\
\text { salsh } \\
\text { sesuai } \\
\text { prosedur }\end{array}$ & $\begin{array}{c}\text { Terdapat } \\
\text { peringatan } \\
\text { bahwa } \\
\text { passirard } \\
\text { salah }\end{array}$ & Berhasil \\
\hline
\end{tabular}

Tabel 1. Balck Box testing Login

12

Uji Manfaat

Berikut ini adalah hasil uji manfaat dari 30 responden yang telah mengisi kuisioner uji manfaat dengan interpretasi hasil sebagai berikut:

\begin{tabular}{|l|l|l|l|l|}
\hline Eficiency & Usbbility & Correctuess & lintegrity & Testability \\
\hline $98,33 \%$ & $94,33 \%$ & $95,56 \%$ & $96,67 \%$ & $96,67 \%$ \\
\hline
\end{tabular}

Tabel 2. Presentase Hasil Uji Manfa 
Rosalina Yani Widiastuti, Endang Setyawati, \& Angela Marici Uba Langobelen, Pengembangan Sistem

\begin{tabular}{|c|c|c|c|c|c|c|}
\hline \multirow{4}{*}{ Eficiency(Efisiensi) } & \multirow{2}{*}{ Kriteria } & \multicolumn{4}{|c|}{ Pertanyaan } & Rata-rata \\
\hline & & P1 & $\mathrm{P} 2$ & P3 & P4 & \multirow{3}{*}{98,33} \\
\hline & $\mathrm{s}$ & 23,33 & 23,33 & 30 & 33,33 & \\
\hline & SS & 73,33 & 76,67 & 70 & 63,33 & \\
\hline \multicolumn{2}{|l|}{ Total } & 96,66 & 100 & 100 & 96,66 & \\
\hline \multirow{4}{*}{ Us ability (Kebergunaan) } & \multirow{2}{*}{ Kriteria } & \multicolumn{3}{|c|}{ Pertanyaan } & & Rata-rata \\
\hline & & \begin{tabular}{|l|} 
P5 \\
\end{tabular} & \begin{tabular}{|l|} 
P6 \\
\end{tabular} & P7 & & \multirow{4}{*}{94,33333333} \\
\hline & $\mathrm{s}$ & 43,33 & 30 & 43 & & \\
\hline & SS & 50 & 66,67 & 50 & & \\
\hline \multicolumn{2}{|l|}{ Total } & 93,33 & 96,67 & 93 & & \\
\hline \multirow{4}{*}{ Correctness (Ketepatan) } & Kriteria & \multicolumn{4}{|c|}{ Pertanyaan } & Rata-rata \\
\hline & Nhitend & P8 & P9 & P10 & & \multirow{4}{*}{95,55666667} \\
\hline & $\mathrm{s}$ & 26,67 & 23,33 & 46,67 & & \\
\hline & SS & 70 & 70 & 50 & & \\
\hline \multicolumn{2}{|l|}{ Total } & 96,67 & 93,33 & 96,67 & & \\
\hline \multirow{4}{*}{ Integrity (Integritas) } & Kriteria & \begin{tabular}{|l|} 
Pertanyaan \\
\end{tabular} & & & & Rata-rata \\
\hline & & P11 & & & & \multirow{4}{*}{96,67} \\
\hline & $\mathrm{S}$ & 16,67 & & & & \\
\hline & SS & 80 & & & & \\
\hline \multicolumn{2}{|l|}{ Total } & 96,67 & & & & \\
\hline \multirow{4}{*}{ Testability (Testabilitas) } & Kriteria & Pertanyaan & & & & Rata-rata \\
\hline & Nhitend & P12 & & & & \multirow{4}{*}{96,67} \\
\hline & $\mathrm{S}$ & 30 & & & & \\
\hline & SS & 66,67 & & & & \\
\hline \multicolumn{2}{|l|}{ Total } & 96,67 & & & & \\
\hline
\end{tabular}

Tabel 3. Rata-rata Hasil Uji Manfaat

\section{SIMPULAN}

Nilai piksel sangat berpengaruh dalam menguaraikan tiga jenis citra berwarna RGB, yang nantinya akan ditransformasikan ke ruang warna HSV (Hue, Saturation, Value). Kelemahan pencahayaan yang tinggi dapat berpengaruh pada saat pengujian yaitu dari penyerapan cahaya pada objek yang berlebihan akan menghasilkan warna dari rata-rata RGB menjadi berkurang. Dilihat dari transformasi ruang warna rgb yang tersegmentasi warna hsv ini cukup baik dalam membandingkan kematangan jambu kristal satu dengan kematangan jambu kristal lain dalam mengambil ciri warnanya, dapat dilihat dari pengujian nilai piksel red, green, blue yang ditransformasikan ke nilai HSV untuk deteksi kematangan buah jambu kristal mempunyai hasil presentase sebesar 91,67\% dari 55 data terbaca benar dan 5 data terbaca salah dari 60 data sampel citra buah jambu kristal matang, sedangkan untuk buah jambu kristal mentah mencapai 90\% dari 36 data terbaca benar dan 4 data terbaca salah dari 40 data sampel citra buah jambu kristal mentah. Dapat disimpulkan dari hasil presentase yang diperoleh yaitu sebesar 95\%, perancangan gui ini dapat digunakan untuk mendeteksi kematangan buah jambu kristal berdasarkan fitur warna. 
Vol 1, No. 1, Agustus 2018: 1 -10

\section{DAFTAR PUSTAKA}

[1] Febri Liantoni, Fitri Nur Annisa, "FUZZY K-NEAREST NEIGHBOR PADA KLASIFIKASI KEMATANGAN CABAI BERDASARKAN FITUR HSV CITRA," JIPI (Jurnal Ilmiah Penelitian dan Pembelajaran Informatika), vol. 03, no. 02, pp. 101 - 108, Desember 2018.

[2] Reni Rahmadew, Gina Lova Sar, Hirlan Firmansyah, "Pendeteksian Kematangan Buah Jeruk Dengan Fitur Citra Kulit Buah Menggunakan Transformasi Ruang Warna HSV," Seminar FORTEI 2019, pp. 166-171, 2019.

[3] Husnul Khotimah, Nur Nafi'iyah, Masruroh, "Klasifikasi Kematangan Buah Mangga Berdasarkan Citra HSV dengan KNN," ELTI, vol. 1, no. 2, pp. 1-4, Desember 2019.

[4] Nina Sularida, Jayanti Yusnah, Ika Purwanti, "Identifikasi Tingkat Kematangan Buah Pisang Menggunakan Metode Ektraksi Ciri StatistikPada Warna Kulit Buah," ULTIMATICS, vol. X, no. 2, pp. 98-102, 2018.

[5] Antonio Ciputra, De Rosal Ignatius Moses Setiadi, Eko Hari Rachmawanto, Ajib Susanto , "KLASIFIKASI TINGKAT KEMATANGAN BUAH APEL MANALAGI DENGAN ALGORITMA NAIVE BAYES DAN EKSTRAKSI FITUR CITRA DIGITAL," Jurnal SIMETRIS, vol. 9, no. 1, ISSN: 2252-4983, pp. 456472, April 2018.

[6] R. Febrizal, "Pengembangan Metode Pengukuran Tingkat Kematangan Buah Jambu Kristal Menggunakan Pengolahan Citra," Fakultas Teknologi Pertanian Institut Pertanian Bogor, pp. 18-23, 2017.

[7] S. N. Indonesia, "Jambu Biji," Badan Standarisasi Nasional, pp. 1-16, 2009.

[8] RETNO NUGROHO WHIDHIASIH, SUGI GURITMAN, PRAPTO TRI SUPRIO, "Klasifikasi Kematangan Buah Manggis Ekspor dan Lokal Berdasarkan Warna dan Tekstur Menggunakan Fuzzy Neural Network," Ilmu Komputer Agri-Informatika, vol. 1, no. ISSN: 2089-6026 2, pp. 71-77, 2012.

[9] Rendy Pratama, Achmad Fuad Assagaf, Firman Tempola, "DETEKSI KEMATANGAN BUAH TOMAT BERDASARKAN FITUR WARNA MENGGUNAKAN METODE TRANSFORMASI RUANG WARNA HIS," Jurnal Informatika dan Ilmu Komputer (JIKO), vol. 2, no. 2, pp. 81-86, Oktober 2019.

[10] Pawit Rianto, Agus Harjoko, "Penentuan Kematangan Buah Salak Pondoh Di Pohon Berbasis Pengolahan Citra Digital," IJCCS, vol. 11, no. ISSN: 1978-1520, 2, pp. 143-154, July 2017,.

[11] Muhamad Nasir, Nanik Suciati, Arya Yudhi Wijaya, "Kombinasi Fitur Tekstur Local Binary Pattern yang Invariant Terhadap Rotasi dengan Fitur Warna Berbasis Ruang Warna HSV untuk Temu Kembali Citra Kain Tradisional," Jurnal Inspiraton, vol. 7, no. 1, pp. 42-51, Juni 2017.

[12] Febri Liantoni, Hendro Nugroho, "Perbaikan Kontras Citra Dengan Ekualisasi Histogram Dan Gaussian Pada Klasifikasi Semangka," JURNAL INFORMATIKA UPGRIS, vol. 5, no. 1, pp. 35-39, 2019.

[13] Indarto, Murinto, "Deteksi Kematangan Buah Pisang Berdasarkan Fitur Warna Citra Kulit Pisang Menggunakan Metode Transformasi Ruang Warna HIS (Banana Fruit Detection Based on Banana Skin Image Features Using HSI Color Space Transformation Method)," JUITA, vol. 5, no. 1, ISSN: 2086-9398, pp. 15-21, mei 2017.

[14] N. W. R. Situmorang, "Penerapan Metode K-Nearest Neighbor Dalam Identifikasi Kesegaran Ikan," Jurusan Teknologi Informasi,Universitas Sumatera Utara, Medan, pp. 16-76, 2019.

[15] R. P. Rakhmawati, "Sistem Deteksi Jenis Bunga Menggunakan Nilai HSV Dari Citra Mahkota Bunga," Skripsi, Fakultas Teknologi Informasi, Universitas STKIUBANK (UNISBANK), Semarang, pp. 2144, 2013.

[16] Karunia Ayuningsih, Yuita Arum Sari, Putra Pandu Adikara, "Klasifikasi Citra Makanan Menggunakan HSV Color Moment dan Local Binary Pattern dengan Naïve Bayes Classifier," Jurnal Pengembangan Teknologi Informasi dan Ilmu Komputer, vol. 03, no. 4, pp. 3166-3173, April 2019. 